\title{
Problematizando as Transições Juvenis na Saída do Ensino Médio
}

\author{
Denise Helena Pereira Laranjeira' \\ Mirela Figueiredo Santos Iriart ${ }^{\prime}$ \\ Milena Santos Rodrigues'
} 'Universidade Estadual de Feira de Santana (UEFS), Feira de Santana/BA-Brasil

RESUMO - Problematizando as Transições Juvenis na Saída do Ensino Médio. Este ensaio discute as transições juvenis em tempos incertos. A crise de sentidos de algumas agências socializadoras, entre elas a escola, em seu potencial de garantir às gerações mais novas uma transição para a vida adulta, interpela educadores e gestores sobre a necessidade de reconhecerem a posição das novas gerações nas transformações sociais. Traremos para o debate alguns dos resultados de uma pesquisa realizada com jovens do campo concluintes do ensino médio e algumas categorias analíticas que demarcam as áreas de estudos sobre juventude, como culturas juvenis e sociabilidades. É significativo reconhecer que o papel da escola na inserção sociocultural e profissional do jovem está por acontecer.

Palavras-chave: Transições Juvenis. Culturas. Sociabilidades. Ensino Médio.

ABSTRACT - Problematizing Youth Transitions at the Completion of Secondary Education. This essay discusses the youth transitions in times of incertitude. The crisis of meanings of some socializing institutions, being the school one of them, in their potential of guaranteeing to the youngest generations a transition towards adult life, questions educators and managers about the need to recognize the position of new generations in social transformations. We will bring into debate some of the results of a research carried out with young people living in rural regions, completing the secondary education, and some analytical categories that define the study field about youth, such as youth cultures and sociability. It is significant to recognize that the role of the school in the socio-cultural and professional insertion of the youth is still far from coming into reality.

Keywords: Youth Transitions. Cultures. Sociability. Secondary Education.

Educação \& Realidade, Porto Alegre, v. 41, n. 1, p. 117-133, jan./mar. 2016. 117 http://dx.doi.org/10.1590/2175-623656124 
Problematizando as Transições Juvenis na Saída do Ensino Médio

\section{Introdução}

Com este ensaio teórico discutiremos a relação entre as sociabilidades juvenis e as estratégias de inserção social numa sociedade cujas instituições tradicionais, sobretudo a escola e a família, vivenciam limites para oferecer ancoragens às transições juvenis. As transições juvenis demarcam momentos de ruptura e reconstrução de novos significados, papeis sociais e posições identitárias, a exemplo da saída do ensino médio e os processos de migração do campo para a cidade (ou do distrito para a sede do município). Tais rupturas exigem a negociação de valores, sentidos e crenças - na relação entre a tradição familiar agrícola e as novas formas de socialização - como mostraremos através de algumas narrativas de jovens em contexto rural.

Compreendemos que as distintas etapas da vida, do ponto de vista biopsíquico e social não são lineares, nem fixas, e sim descontínuas e complexas. Ou seja, entendemos tais etapas como ciclos de vida que não se encerram em si mesmos, mas são demarcados por elementos de ordem social, ideológica, cultural e política que delimitam tempos e espaços juvenis, como as condições social e geracional.

Em uma sociedade em mudança, marcada, paradoxalmente, por grandes avanços tecnológicos, comunicacionais, econômicos e socioculturais, e, ao mesmo tempo, por acentuadas desigualdades, sobretudo educacionais, intra e inter-regionais, os jovens têm enormes desafios a enfrentar no delineamento dos seus projetos de vida. No plano histórico e da realidade objetiva, tratando-se da sociedade brasileira, temos uma distância ainda enorme a percorrer para atingirmos um Estado de direitos assegurado a todos os cidadãos no que toca, sobretudo, às políticas sociais públicas, na melhoria da qualidade de vida e equidade social.

Com relação às políticas para a juventude, podemos enunciar algumas conquistas - resultado da força dos movimentos sociais nos últimos 10 anos - a exemplo da emenda constitucional (n. 65/2010, que altera o artigo 227 da Constituição) assegurando os direitos nas distintas esferas como saúde, educação, profissionalização, cultura, segurança, etc. O mencionado artigo reconhece o Estatuto da Juventude (Lei n. 12.852/2013) com a finalidade de regular os direitos dos jovens, como também o Plano Nacional da Juventude, com duração de dez anos. que tem por fim "a articulação das várias esferas do poder público para execução de políticas públicas”. O Estatuto da Juventude amplia a faixa etária deste segmento compreendido entre 15 e 29 anos e apresenta uma agenda de prioridades para garantir a integração social dos jovens, como um ator social importante na dinâmica social ${ }^{1}$.

Observamos uma crise de sentidos no papel de algumas agências socializadoras tradicionais, como por exemplo, a escola em integrar as novas gerações no plano político e social, em uma sociedade, como a brasileira, marcada entre outros fatores, por fortes desigualdades so- 
ciais, raciais, de orientação sexual e de gênero. Conjugado ainda, à fragilidade dos laços sociais e de filiação intergeracional ${ }^{2}$, este estado de coisas, interpela educadores e pesquisadores sobre a necessidade de reconhecermos a posição das novas gerações como potenciais autores na dinamização cultural e nas transformações sociais. Diante do contexto sociopolítico, em sua dimensão pública, os jovens têm potencial para exercer protagonismo, a exemplo dos movimentos culturais de periferia, ou ainda dos movimentos coletivos organizados, na reivindicação de direitos sociais e políticos, em seus diferentes territórios.

Vale mencionar, no entanto, que os jovens não costumam ter suas experiências de sociabilidade reconhecidas, muitas vezes, nos espaços escolares. Nossas investigações confirmam tal fato. É preciso considerar as experiências dos jovens, originárias de seus contextos singulares de vida, carregadas de sentido no presente e em seu vir a ser, como campo de possibilidades, articulando-as às estruturas de oportunidade e às mediações sociais - seja pela relação escola, família e comunidade, seja pela participação estudantil, ocupação de espaços políticos ou através das culturas juvenis, como discutiremos mais adiante.

Neste sentido, categorias analíticas como culturas juvenis ${ }^{3}$ e sociabilidades, vêm dinamizando o campo de estudos sobre juventude, ao proporem não dicotomizar a relação entre sujeito, cultura e instituições sociais e considerarem os/as jovens em seu potencial de apropriação e transformação dos elementos da cultura hegemônica, instituindo-os de novas possibilidades de inserção social.

\section{Os Processos de Socialização e de Transmissão Cultural no Contemporâneo}

Ao tomarmos a juventude como categoria social, admitimos a sua posição na ordenação da sociedade, não como mera passagem para a vida adulta, mas como grupo que tensiona os espaços sociais e geracionais, numa conjuntura em que as formas de participação, os cenários políticos, a organização do trabalho se transformam rapidamente. Acompanhando o pensamento de Martuccelli (2007, p. 10) é necessário nesse cenário, reconhecer as diferentes experiências vividas pelos/ as jovens, "Progressivamente se impõe a necessidade de reconhecer a singularização crescente das trajetórias pessoais [...]”, em que os sujeitos produzem respostas aos desafios de toda ordem, com os quais se defrontam em seu cotidiano, construindo suas biografias na interação com as contingências sócio-históricas que as delineiam.

Os processos de socialização no passado, como nos atualiza Melucci (1997, p. 5-6) eram compreendidos como “[...] transmissão básica de regras e valores da sociedade[...]", na atualidade, tais processos se apresentam como "[...] possibilidade de redefinição e invenção das capacidades formais de aprendizado, habilidades cognitivas, criatividade". 
Problematizando as Transições Juvenis na Saída do Ensino Médio

Embora analisando o movimento estudantil no contexto das rebeliões juvenis do final da década de 60, a obra de Foracchi (1972) tem grande atualidade. A formação de novos agentes sociais (os/as estudantes assim o seriam ou deveriam ser), em suas palavras é fundamental para a "preservação e transmissão do patrimônio cultural, uma garantia de continuidade e de renovação" (Foracchi, 1972, p. 22). Sem isso, não haveria - como também via Mannheim (1968) - a possibilidade do novo no plano societário, pois “[...] a nova vida só será vivida pelas gerações mais moças” (1968, p. 72).

Claro estava para Foracchi (1972) que os processos de transição na sociedade moderna eram difíceis e complexos, associados a um sistema (normativo, econômico e político) em crise, que refletiriam sobre a juventude ("categoria histórica e social") ${ }^{4}$, expondo o estado de tensão frente à sociedade.

Os limites das instâncias socializadoras, debatidos na atualidade, também foram bem notados pela mesma autora (1972, p. 23) ao lembrar dos questionamentos sobre a "eficácia dos recursos de socialização [...]", e da "[...] validade dos recursos institucionais como alternativas para a organização da vida pessoal”. Assim, como formar novos agentes sociais, sem considerar o contexto histórico, político e econômico, marcado por políticas neoliberais que atravessam fronteiras e acirram as desigualdades. As demandas de um grupo social (e aqui tratamos da juventude) quando não atendidas, instam a ruptura da ordem, as manifestações vêm à tona e refletem o desejo da instauração do novo, que pode ser traduzido pela implementação de uma agenda propositiva no campo das políticas sociais nas cidades e no campo.

Na mesma linha, Dubet (2003), analisando a situação dos jovens franceses, observa o paradoxo entre a esperança ou as expectativas criadas pelos jovens, e o não atendimento por parte do Estado e da sociedade às suas demandas objetivas. Se atualizamos o debate, essa tensão gera o confronto, por vezes fugazes, e, ao mesmo tempo, intensos com as diferentes esferas do poder, como ocorrido no Brasil e em outros países (Chile, Grécia, Egito, Turquia, entre outros). Sabe-se que existem especificidades dos movimentos. No caso brasileiro, o aumento da tarifa do transporte urbano, foi a faísca que se alastrou para tantas outras demandas (educação e saúde pública de qualidade; moradia, locomoção na cidade, segurança etc.); os jovens secundaristas chilenos se rebelaram contra a mercantilização do ensino, pela democratização do acesso ao ensino superior etc.; os gregos foram às ruas sobretudo por questões econômicas do país, com elevação das taxas de desemprego; no Egito, mudanças no regime político, os jovens lutaram por maior liberdade e democracia política; e na Turquia, a relação público/privado gerou o estopim em defesa de uma praça pública, contra a instalação de um edifício comercial em seu lugar.

Enfim, se há particularidades em tais movimentos, há também aproximações, dadas as conexões entre o local e o global. Do ponto de 
vista de Zizek (2013, p. 103-104), “O capitalismo global é um processo complexo que afeta diversos países de maneiras variadas, e o que unifica tantos protestos em sua multiplicidade é que são todos reações contra as múltiplas facetas da globalização capitalista”. Uma das facetas, sem dúvida tem ligação direta com o não-lugar ocupado pela educação nas políticas públicas, seja no plano da infraestrutura (bibliotecas, laboratórios, salas adequadas), dos recursos humanos, lembrando a formação docente, os salários e planos de carreira defasados; o que atinge diretamente os jovens, sobretudo dos estratos mais pobres e/ou da zona rural, na transição entre escola, trabalho e inserção social.

Se a juventude não é uma condição meramente biológica, mas também cultural (Manheim, 1968), compreendemos que as experiências e/ou vivências apresentam-se como fatores importantes na construção e fortalecimento identitário, bem como na autonomia dos sujeitos. A experiência em sua diversidade (cada vez maiores no contemporâneo), marcadas por limites, riscos e possibilidades nos planos cognitivo, afetivo, cultural e material (Melucci, 1997; Madeira, 2006), traz elementos de diferenciação, como bem posto por Melucci (1997).

Podemos pensar que as culturas juvenis são expressões singulares a partir das quais os jovens constroem significados para lidar com um mundo cada vez mais complexo, em que as formas de participação, os cenários políticos, a organização do trabalho se transformam rapidamente. São os jovens que vivenciam de forma mais intensa a tensão entre as forças instituídas e as instituintes na dinâmica social, em face das desiguais oportunidades em relação a gênero, etnia e classe social, mas, sobretudo em relação à circulação, acesso e distribuição dos bens culturais.

Comungando com a perspectiva de Pais (2003), o conceito de cultura juvenil ganha maior dinamismo e concretude, quando recorre ao seu sentido antropológico, portanto, voltado para modos de vida específicos e práticas cotidianas, “[...] que expressam significados e valores não apenas ao nível das instituições, mas também ao nível da própria vida cotidiana" (Pais, 2003, p. 69). Em face de uma socialização integradora, no sentido da adequação social, podemos entender as culturas juvenis como autonomia criativa, que visa ao protagonismo, no seu sentido de diferenciação e de participação social.

$\mathrm{O}$ indivíduo emerge enquanto individualidade frente ao entrelaçamento dos distintos círculos com os quais compartilha relações, portanto, é desta diversidade permeada por conflitos, rupturas e oscilações que despontam também as possibilidades de expansão e enriquecimento da vida social, num movimento perpétuo de sua recriação constante (Martuccelli, 2000, p. 383 e 392, nossa tradução).

Amplia-se esse entendimento a partir de Simmel (2006, p. 84), ao considerar que "O conflito entre a sociedade e o indivíduo prossegue no próprio indivíduo como luta entre as partes de sua essência”. De um 
Problematizando as Transições Juvenis na Saída do Ensino Médio

lado, na perspectiva de totalidade e unidade orgânica, a sociedade cobra integração do indivíduo ao instituído; de outro, o indivíduo, "Ele quer ser pleno em si mesmo [...] ele quer desenvolver a totalidade de suas capacidades, sem levar em consideração qualquer adiamento exigido pelo interesse da sociedade".

Podemos nos reportar aos elementos de tensão no processo socializador das novas gerações, presentes nas relações entre jovens, família, escola e sociedade: tanto em relação às dimensões múltiplas da sua identidade (jovem, estudante e trabalhador), como aos contextos que habitam (rural-urbano).

As expectativas e possibilidades de integração social são geradas a partir de relações concretas no plano sociocultural, econômico e político, vivenciados por indivíduos e estratos sociais em dado tempo e espaço.

Sabemos que as oportunidades para que os /as jovens vivenciem uma gama diversa de experimentações em seu sentido mais amplo, são desigualmente distribuídas no contexto social. Madeira (2006, p. 140), emprega a expressão "juventude roubada" para definir a situação dos (as) jovens brasileiros das classes populares que ao anteciparem a vida adulta, seja pela inserção precoce no trabalho ou pela gravidez, não usufruem das experimentações - afetivas, biopsíquicas e cognitivas (quadro que afeta sobretudo estudantes da escola pública) - típicas de um breve ciclo da vida, importantes para a vida adulta.

Vale dizer, ainda, que o espaço social, a exemplo da escola, não é neutro, mas campo de disputas, lócus da "estrutura das distribuições" e imposição de princípios e divisões que passam pelos campos da etnia, região, nação, classe, etc. (Bourdieu, 2001, p. 224).

É possível problematizar concepções de educação formal que tanto não levam em conta as experiências pertinentes às práticas vividas pelos jovens em seus territórios, quanto os tempos diferenciados daqueles que se encontram no mundo rural, sob uma lógica de vida cotidiana distinta da urbana, mas que a ela é associada nas relações de produção, consumo e serviços.

No caso específico da educação ofertada aos jovens em contextos rurais, os problemas estruturais da escola pública, aparecem de forma ampliada: deficiências na formação específica dos docentes, na infraestrutura, no transporte, dentre outras.

Em relação à juventude rural, Carneiro (2005) aponta como a escola "preenche idealmente" o imaginário juvenil na construção de seus projetos individuais. Nestes, a melhoria de vida aparece, quase sempre, atrelada à conquista do mercado de trabalho. Como afirma a autora o espaço escolar "não tem importância apenas como um meio facilitador do acesso ao mercado de trabalho, ela se destaca como importante espaço de sociabilidade” onde se faz amigos (Carneiro, 2005, p. 251). 
Entre apostas e incertezas sobre a escola, os jovens que vivem no distrito rural de São Josés, onde realizamos a pesquisa Juventude Escolarização e Inserção social: um estudo em diferentes contextos da rede pública de educação no município de Feira de Santana (FAPESB, 2008-2010), têm na escola, uma referência da existência do poder público, pois este parece se mostrar pouco presente no atendimento a outras importantes demandas juvenis ligadas à cultura, ao lazer e à formação profissional.

Os estudantes (20) entre 18 e 23 anos, concluintes do ensino médio, cuja maioria não trabalha formalmente mas auxiliam os pais na lavoura, expressam seu anseio com o término do ensino médio e as reais possibilidades de inserção socioprofissional, quando reclamam que a escola apresenta-se desconectada da realidade e das suas demandas. Fato observado por Nora Krawczyk (2014, p. 86) ao refletir sobre o ensino médio e o sistema educacional na atualidade. A organização e o funcionamento destas instâncias, marcadas pelas verticalidade e rigidez burocrática, apresentam um descompasso com o momento histórico, o que acaba por comprometer qualitativamente o trabalho educativo e a própria democratização do conhecimento.

No entanto, apesar dos seus limites, estar fora da escola, para estes jovens, tornariam as transições incertas e ainda mais frágeis.

Porque sem os conteúdos a gente não vai conseguir hoje em dia nada. Sem o colégio sem o conteúdo que a gente tem hoje, a gente não consegue. Tem que tá informado, inda mais agora na era da informática nós temos sempre que tá informado, o colégio hoje, embora que seja 'órfão' de um jeito ou de outro, não traz toda a realidade pra gente, mas, ele é o caminho (sexo feminino, 19 anos).

Se eu não tivesse na escola hoje eu taria [...] por ai jogado pelo mundão! Porque a escola é aquela onde forma na verdade... O foco da escola é preparar o aluno pra ser alguém! (sexo masculino, 20 anos).

Eu via o Ensino médio como algo assim de ouro! Porém para mim hoje é só mais uma aproximação para terminar os estudos. Porque o ensino na verdade é o mesmo, o objetivo de ensinar é o mesmo. Então o ensino médio é só isso mesmo $1^{\circ}, 2^{\circ}$ e $3^{\circ}$ ano, é só mesmo para terminar os estudos, nada mais (sexo masculino, 20 anos).

Os estudantes sabem da fragilidade da escolarização que receberam, não se sentem preparados nem para o vestibular, nem para o mercado de trabalho, mas, ainda assim, sabem que concluir o ensino médio é o mínimo, como bem disse um dos jovens em um dos grupos focais?

Para os jovens em contexto rural, muitas vezes, a distância entre as localidades onde moram e a cidade, as limitadas opções e locais de lazer reduzem as experiências de sociabilidade com seus pares. Nesse sentido, a escola assume a função de suprir tais carências, constituindo-se um importante espaço de encontro, de resenhar ${ }^{8}$, de formação pessoal e social e também de projeção de um futuro, mesmo que incerto.

Percebemos a centralidade da escola e da família como contextos de referência e organizadores das experiências de vida juvenil. Os 
Problematizando as Transições Juvenis na Saída do Ensino Médio

jovens foram quase unânimes em destacar, na discussão em grupo, o espaço de encontro e de convivência como os maiores predicados da escola:

O que eu mais gosto na escola são os meus amigos (sexo feminino, 19 anos)

Gosto mais é da resenha (sexo masculino, 18 anos)

Eu acho também assim é o relacionamento, porque como eu poderia imaginar conhecer, assim, tantas pessoas, como se não fosse a escola? Um exemplo: Marluce mora a mais de cinco quilômetros da minha casa, eu nunca poderia imaginar conhecer ela se não fosse a escola (sexo masculino, 20 anos).

Setton (2005) questiona o papel das agências tradicionais de socialização no contemporâneo, a partir da emergência de uma nova ordem sociocultural caracterizada por uma maior circularidade de experiências e referências identitárias, em que se leve em conta a pluralidade cultural $^{9}$. A cultura de massa e todo o seu aparato tecnológico, com forte caráter socializador, levam Setton (2012) a considerar que a família e a escola vêm perdendo o monopólio na socialização das novas gerações.

A partir do conceito de hibridação de Canclini (2010), a autora recorre à ideia de multiculturalismo não apenas como fusão de valores, mas significando uma variedade de estratégias de apropriação cultural, em que se considere o movimento dialético, criativo e contraditório do processo socializador.

A escola, como instituição socializadora na formação dos jovens tensiona-se com uma heterogeneidade de espaços de socialização juvenil, sendo que cada vez mais "[...] a construção das identidades sociais dos indivíduos passa a ser mediada pela coexistência de distintas instâncias produtoras de valores e de referências culturais" (Setton, 2012). Estes elementos de tensão, são visíveis, por exemplo, especialmente no ensino médio, nas interações professor-aluno, pautadas nas relações de poder, quando confrontam-se normas escolares e normas dos grupos de pares (Krawczyk, 2014; Dayrell; Carrano, 2014).

Notamos que os jovens, nas fronteiras entre o rural e o urbano ${ }^{10}$, além de conviverem com elementos da tradição familiar agrícola, também estão conectados aos dispositivos tecnológicos, que ampliam sua participação no mundo, mas a escola ainda é o contexto mediador entre a vida pública e a vida privada, por excelência, mesmo que não mais único e exclusivo, como relativizado pela reflexão feita por alguns dos jovens no grupo focal.

\section{A Trama da Vida nos Processos de Transição e a Saída do Ensino Médio}

Zittoun et al. (2013) convidam-nos a pensar no movimento de continuidades e mudanças que configuram o curso de vida. As transições 
juvenis envolvem processos de ajustes mútuos e dinâmicos em diferentes aspectos da sua existência: da aprendizagem - elaboração de novas formas de ação e de entendimento do mundo, do outro, de si mesmo; da identidade em mudança - transformação e criação de novas posições identitárias e dos processos de significação, por meio dos quais o indivíduo elabora suas experiências com os outros, conferindo sentidos ou as ressignificando. Tais mudanças ocorrem de forma interdependente e em ambientes físicos, sociais, geográficos e simbólicos que facilitam ou limitam as experiências em transição.

Na perspectiva do curso de vida, a dimensão da temporalidade é um organizador das experiências humanas, tanto no sentido da irreversibilidade, pois uma ação realizada é uma ação que não tem volta (passado), assim como da imprevisibilidade e abertura para o novo (futuro), quando projetamos mundos possíveis ou respondemos a novas situações. A etapa da adolescência, na concepção de Zittoun et al. (2009), abre-se para a perspectiva de planejar e antecipar estratégias de ação no futuro, ao mesmo tempo em que os sujeitos constroem significados no presente, através do uso de recursos simbólicos (imaginação, criatividade, pensamento). A função semiótica através da internalização de elementos culturais, possibilita a reflexividade e o distanciamento, necessários para responder às mudanças e demandas externas em constante movimento.

Há, portanto, de se reconhecer, que as passagens ou transições pelas etapas do ciclo de vida não harmoniosas e lineares, estão sujeitas a conflitos, expressos nas descontinuidades ou rupturas como já pontuaram, dentre outros, Arendt (2011); Foracchi (1972); Mannheim (1968), Melucci (1997); Zittoun et al. (2009; 2013).

Madeira (2006) faz um alerta ao dizer que o modelo de transição linear, que prepara os jovens para a entrada na vida adulta, não acontece com todos os brasileiros da mesma maneira. Os detentores de maior renda e nível de escolaridade, naturalmente a menor parcela da sociedade, ao terem oportunidade de vivenciar as etapas de escolarização em sua plenitude, conseguem alcançar comportamento semelhante ao dos outros países desenvolvidos e emergentes. Vale citar a pesquisa desenvolvida por Guerreiro e Abrantes (2005) com adolescentes e jovens portugueses. Observam aspectos semelhantes aos estudos de Madeira (2006) realizados no Brasil. Na tipificação feita pelos autores para analisar os diferentes processos de transição para a vida adulta, encontram-se entre outros, o tipo profissional (quando os sujeitos relegam para um futuro mais distante os projetos relacionados à constituição da família e o lazer; ou da transição em dois tempos; o lúdico (a opção pelo prolongamento da adolescência, assim a centralidade da "fruição e da errância”); a experimental (saída de casa, imprevisibilidade no modo de vida, modelo culturalmente valorizado, porém sua prática é residual pelas dificuldades de auto sustentação); a precoce (típico das classes populares, inserção no trabalho, fraca aspiração escolar, limitação na esfera 
Problematizando as Transições Juvenis na Saída do Ensino Médio

do lazer, presença da maternidade...); a precária (trabalhadores descartáveis).

Segundo Ribeiro (2011, p. 27), a maioria dos jovens brasileiros traz desde a infância uma significativa defasagem idade-série escolar, o que representará demanda para a Educação de jovens e adultos (EJA). Completa a autora, ao lembrar que aproximadamente 60 milhões de indivíduos não concluíram o ensino fundamental. Enquanto apenas $25 \%$ dos jovens encontram-se em situação regular, isto é, com adequação idade e série. Frente a esse quadro, e refletindo sobre as falas dos sujeitos da pesquisa, que não por acaso, apresentam a referida inadequação (característica sobretudo da região Nordeste), acompanhamos alguns dos questionamentos feitos por Ribeiro (2011): "Com quais trajetórias experienciam os processos escolares e educativos? O que agregam de conhecimento? As credenciais escolares que os jovens mais pobres têm conquistado garantem benefícios educacionais semelhantes aos usufruídos pelos setores sociais mais privilegiados? O aumento da escolaridade tem postergado a entrada de jovens pobres no mercado de trabalho? Com que idade esses jovens chegam ao final do ensino fundamental e médio?".

Krawczyk (2014, p. 84), a partir dos dados de matrículas de estudantes na faixa etária entre 15 e 17 anos de idade, no ensino médio (PNAD/IBGE, 2009), mostra os níveis de matrículas ainda baixos nesta etapa escolar, embora sua evolução, como observado a seguir. A taxa líquida de matrículas no período 1991 e 2010, evoluiu de $17,3 \%$ para $32,7 \%$, chegando a $44,2 \%$ em 2004 e a 50,9\% em 2009. Contudo, apropriadamente nota a autora que a "outra metade", ainda estaria no ensino fundamental (34,3\%), com históricos de reprovação ou ingresso tardio ou ainda sem frequentar a escola, o que revela as lacunas no processo de democratização escolar. Acrescentamos, tal processo atinge, como se sabe, em maiores proporções jovens negros e pobres, ou seja, os componentes étnico-raciais, de classe, entre outros, aí conjugam-se de maneira a multiplicar as desigualdades sociais e econômicas, e em última instância o acesso digno aos incertos e já precários postos de trabalho.

Alguns jovens entrevistados durante a nossa pesquisa, revelaram estratégias de negociações na saída do ensino médio, quando direta ou indiretamente, assumem a responsabilidade de romperem com trajetórias biográficas ligadas à tradição familiar agrícola, através do processo de escolarização. Para a maioria dos pais desses jovens a escola, com a conclusão do ensino médio, promoveria uma passagem quase mágica de acesso ao mercado de trabalho. O estudo é visto como principal caminho para abrir novas alternativas ao "trabalho penoso" do campo e as incertezas sobre o futuro da atividade agrícola. Nessa perspectiva a educação ganha contornos bem específicos. Para pais e filhos a educação é a oportunidade de ser "alguém" na vida, isto é, a conquista de um bom emprego.

126 Educação \& Realidade, Porto Alegre, v. 41, n. 1, p. 117-133, jan./mar. 2016. 
No relato da jovem mãe entrevistada, fica clara essa responsabilidade, pois ela não apenas ultrapassa a escolarização de seus pais, como a de seus irmãos.

Tenho quatro irmãos, cinco comigo. Meus dois irmãos não estudam, pararam. Meu irmão mais velho parou no $1^{\circ}$ ano, o de junto dele parou acho que na $5^{\circ}$ ou $6^{\circ}$ série, e minha irmã mais velha tava fazendo $2^{\circ}$ ano e a mais nova parou na $7^{\circ}$ série. Tive dificuldades mesmo quando eu tive meu filho, eu tava na oitava série, ai eu parei na oitava.[...] Eu pensei em voltar em primeiro lugar pelo meu pai, porque ele fica muito feliz quando vê que a gente ta estudando, que a gente quer alguma coisa, porque ele quer que o futuro da gente não seja igual o dele, ai é muito incentivo dele. Ele falava; "Ah você engravidou e não vai continuar estudando"? A gente ficava vendo assim ele triste, vendo que ele não queria isso pra gente, então eu voltei a estudar, assim, pra satisfazer a vontade dele e quem sabe arrumar um emprego. Mas ele [referindo-se ao pai] nunca desistiu da gente [...] (sexo feminino, 19 anos).

Ao difícil processo de saída do ensino médio ${ }^{11}$, se somaria outra transição, a do ambiente rural para o urbano. Ao analisarmos como os jovens pensam e constroem suas estratégias de transição, ficam evidentes as dificuldades para efetivá-las e as distintas posições entre o desejo de permanecer em seu território (reconhecendo os entraves para a inserção no mundo do trabalho) e o de buscar alternativas na "cidade grande”, promessa de maior sucesso na escolaridade e na inserção socioprofissional:

Não! Eu não quero de jeito nenhum sair daqui. Eu só vejo gente falar: "Ah, eu vou me mudar!" eu não quero não. O problema aqui são as oportunidades, porque emprego não tem. Mas se tivesse? Ia ser uma maravilha! (sexo feminino, 19 anos).

Porque a estrutura da zona rural ela é muito baixa, assim em relação de conhecimento. Então eu só penso em morar ou numa cidade grande, né ? [...] Porque o conhecimento lá é bem maior, então quero aprimorar meus conhecimentos. Ela [zona rural] não me oferece oportunidades de estudos e de emprego (sexo masculino, 20 anos).

Muitas vezes, o migrar é paradoxalmente tramado como estratégia fundamental para a manutenção da família no campo. Ter um único membro migrante, às vezes é condição para a sobrevivência e a permanência do restante do grupo familiar no campo. A saída, então, muitas vezes representa uma etapa de uma trajetória, que pode ser marcada por múltiplos movimentos de idas e vindas (migrações sazonais ou definitivas), mas a referência do campo e de suas famílias permanece como um ancoradouro para esses jovens. Nestes casos, a escolha sobre os seus destinos é tributária das condições reais de permanência da vida no campo, ou seja de uma escolarização qualificada, de oportunidades de emprego e renda.

Os jovens reconhecem que levam um repertório de habilidades e conhecimentos bastante restritos para enfrentar, tanto o mercado de 
Problematizando as Transições Juvenis na Saída do Ensino Médio

trabalho, quanto o ingresso no ensino superior. Mecanismos de acesso ao ensino superior como o Exame Nacional do Ensino Médio (ENEM), Programa Universidade para Todos (ProUni) e as políticas de cotas sociais e raciais ainda parecem ter impacto pequeno na construção de planos e projetos futuros para os jovens entrevistados. As menções a tais políticas e programas públicos foram escassas, revelando pouco conhecimento sobre os mesmos.

Durante os grupos focais, os/as jovens da escola rural puderam esclarecer como pensam a articulação entre a continuidade dos estudos e a perspectiva laboral. Observamos a centralidade do trabalho nas suas trajetórias de vida, assim como a formação profissional, como etapa precedente. Para a maioria deles, os caminhos mais viáveis para a saída do ensino médio seriam: 1) conseguir algum trabalho remunerado para poder investir em algum curso profissionalizante; 2) realizar algum curso profissionalizante para aumentar as chances de inserção profissional qualificada; e 3) ingressarem em cursos de nível superior.

Em tal contexto é um desafio para a escola atual tematizar questões caras aos jovens como a difícil inserção profissional num mercado inconstante, exigente e competitivo. Outro desafio é o reconhecimento das suas demandas para efetivarem a transição social na saída do Ensino Médio. Seria necessário: melhorar a qualidade do ensino, ampliar os mecanismos de diálogo e participação estudantil, ampliar as redes de suporte social e tecnológico. Enfim, sem considerar o jovem como interlocutor válido em questões que lhe dizem respeito, como o próprio currículo escolar, torna-se difícil estimular o protagonismo juvenil e garantir a "centralidade dos jovens estudantes [do ensino médio] sujeitos do processo educativo”, ademais, como previsto pelas próprias Novas Diretrizes Curriculares para o Ensino Médio (Dayrell; Carrano, 2004, p. 103).

Segundo Mônica Molina (2015) a escola rural ou urbana deve não apenas assegurar os saberes universais, mas aqueles saberes (relativos aos meios de produção e à cultura local) que portam os jovens a partir de suas "comunidades" de origem. ${ }^{12}$ Em se tratando da escola rural, por exemplo, projetos de agroecologia e sustentabilidade poderiam ampliar as oportunidades de permanência ao território, por exemplo, como observa a autora, combinando o sistema de valores transmitidos pela família de tradição agrícola, com os símbolos culturais que caracterizam formas de pertencimento juvenil.

\section{Considerações Finais}

São nas relações de sociabilidade mais próximas, como as de amizades, tecidas primordialmente, como observamos no espaço escolar e nas diversas formas de associação juvenil, que os jovens encontram dispositivos sociais de subjetivação e desenvolvem relações de pertencimento mais significativas. 
Quando os jovens opinaram sobre a experiência escolar, notamos a distância entre o projeto institucional e os projetos pessoais, o que nos remete à indefinição dos objetivos do ensino médio na mediação para a vida adulta (inserção socioprofissional e projetos de futuro).

Em alguns casos, comparam-se a outros (as) jovens que se encontram fora da escola, desempenhando trabalhos braçais ou dedicando-se ao cuidado dos filhos. Assim, atribuem a si mesmos uma posição de elite por estarem concluindo o ensino médio, embora reconhecendo que levam um baixo repertório social e cultural para concorrer a postos de trabalho mais qualificados ou ao ensino superior.

Os elementos de tensão entre escola, família e trabalho foram explicitados pelos/as estudantes entrevistados/as. Seja em relação ao distanciamento da escola à suas demandas reais, ou ainda pela fragilidade de identificação com o rural, quando a cidade aparece como promessa de realização pelo acesso ao trabalho, consumo e formação profissional.

Percebemos que nos seus modos de se identificar, os/as jovens se encontram diante de repertórios híbridos, tributários de elementos sócio-histórico-culturais que delimitam o universo rural, bucólico e romântico - também demarcado por uma organização social com centralidade no trabalho árduo - com elementos contemporâneos das sociedades tecnológicas globalizadas, reivindicando por espaços de participação cultural menos institucionalizados.

Nessa direção, colocam-se desafios institucionais, políticos e sociais, que reconheçam os tempos e espaços juvenis, como o direito à cidade - sem também perder de vista o direito à vida digna no campo -, em que se instituam práticas educativas mais dialógicas, garantindo o verdadeiro acesso aos saberes universais e locais, que os posicionem como participantes ativos na construção da cultura, com potencial de ação no presente e com vistas a pensar e projetar o futuro, como sujeitos trajectivos (Pais, 2006). Mas para tanto, a escola pública, teria que superar seu estado de orfandade - no dizer de uma das jovens -, e tornar-se de fato prioridade nas políticas públicas, continuar garantindo não apenas o ingresso e a mera certificação, mas a permanência de crianças e jovens, oferecendo-lhes uma formação de qualidade, preparando-os/ as para a vida em seu sentido mais amplo: intelectual, moral, estético e profissional.

As redes interativas e intercomunicativas construídas como marcas de participação juvenil na contemporaneidade, são dispositivos importantes na compreensão das formas de apropriação e recriação da herança cultural, através de processos de sociabilidade e oportunidades que tornam os jovens mais autônomos e agentes de seu destino. Em relação aos espaços formais de educação, o que se observa é que a transmissão geracional ainda está marcada pela verticalidade e regida pela lógica adultocêntrica.

Educação \& Realidade, Porto Alegre, v. 41, n. 1, p. 117-133, jan./mar. 2016. 
Problematizando as Transições Juvenis na Saída do Ensino Médio

É preciso escutar e aprender com os jovens a construção de táticas e tessituras para enfrentar o presente em seus obstáculos, sobretudo para as classes populares, de forma a potencializar e amplificar oportunidades com vistas a projetos de futuro a serem tecidos com arranjos de curto prazo e em grande medida na aposta criativa. Estar atento às culturas juvenis, como forma re-ativa de instituir expressões mais libertárias de existência, nas margens da cultura hegemônica, como - recorrendo à Pais (2005) - "território de crítica aos poderes estabelecidos".

Cabe aos próprios sujeitos de direito na cidade e no campo, aos gestores, aos educadores e aos governantes das distintas esferas - federal, estadual e municipal - o enfrentamento crítico e construtivo que resultem em implementações de práticas pedagógicas e políticas que ultrapassem o plano das promessas, visando a garantia dos direitos sociais, incluído aí os educacionais, já garantidos constitucionalmente.

Recebido em 30 de maio de 2015

Aprovado em 17 de dezembro de 2015

\section{Notas}

1 Ver em: <http://juventude.gov.br/estatuto>.

2 Compreende-se que as relações intergeracionais de padrão vertical são pouco permeáveis, seja nos contextos da família, da escola, do trabalho e da política, quando poderiam, senão garantir, ao menos propiciar às gerações mais novas uma transição para a vida adulta pautada em valores associados à autonomia, à criatividade, à alteridade e à ética.

3 Segundo José Machado Pais (2006, p. 62) as culturas juvenis podem ser analisadas pelas "[...] socializações que as prescrevem [teorias das gerações ou de enfoques classistas] ou pelas expressividades (performances) cotidianas". Reconhecidos os limites das abordagens classista e geracional, o autor nota a fertilidade da perspectiva que valoriza o campo da experiência (não desconectando-o das relações estruturais), lá onde brotam os fazeres, os desejos e as circunstâncias vividas e interpretadas in loco pelos seus atores.

4 Nas palavras da autora (1976, p. 12), a noção de juventude como "categoria história e social", ocorre quando temos um "movimento de juventude", ou seja, compreendida enquanto "produto histórico". Esse entendimento, revela que uma análise consequente não se limita às relações geracionais, mas, vai além, reflete sobre uma ordem social estabelecida, no caso, à época e na atualidade, como notamos, inibidora de realizações e integração digna e plena dos atores sociais.

5 Distrito do município de Feira de Santana-Ba, com aproximadamente 2.300 hab., distante aproximadamente 12 quilômetros da sede, apesar da proximidade é caracterizado fortemente pela pequena pecuária e agricultura familiar. Apresenta pequena oferta de serviços públicos, entre eles a educação e o transporte são tidos como precários. A oferta de emprego também reduzida, se limita principalmente ao comércio informal. Uma única escola atende estudantes na modalidade Educação de Jovens e Adultos (EJA) no período noturno, e ensino fundamental e médio no período diurno.

6 A referida pesquisa teve como objetivo compreender os significados sobre a escolarização e os projetos de futuro entre jovens ( 14 a 23 anos), em duas escolas

130 Educação \& Realidade, Porto Alegre, v. 41, n. 1, p. 117-133, jan./mar. 2016. 
públicas de ensino médio, em contexto urbano e rural, utilizando instrumentos quantitativo (questionário) e qualitativos (grupos focais e entrevistas). Neste artigo focaremos as narrativas produzidas por jovens de ambos os sexos, na maioria negros, moradores do contexto rural, concluintes do ensino médio.

7 Foram realizados três grupos focais mistos, na escola, tematizando questões como os sentidos da escola, pensar o presente e o futuro, o que é ser jovem em contexto rural. O uso de grupo focal no contexto escolar, com jovens no ensino médio, mostrou-se uma estratégia metodológica adequada, já que este provoca a possibilidade de fala e compartilhamento de experiências entre pares. Sobre as técnicas de grupo focal consultar: Gatti, Bernadete, 2005; Weller, Wivian 2010.

8 Termo nativo utilizado com frequência pelos estudantes para se referir ao tempo-espaço de conversar e se atualizar das experiências uns dos outros, nos interstícios da ordenação e rotina escolar.

9 O documentário Diz Aí Juventude Rural: identidades é expressivo desta pluralidade nos marcos identitários juvenis presentes em nosso país e tão pouco conhecida. Isso para tomarmos como referencia a realidade dos jovens que moram em áreas rurais em distintas regiões que abrangem o Norte, Nordeste, Sul e Sudeste e Centro-Oeste, com suas peculiaridades na música, na alimentação, nas vestimentas, no lazer, na tecnologia, nas sociabilidades, enfim na cultura. Disponível em: <https://www.youtube.com/watch?v=AlhqskKjriw >.

10 Segundo Souza (2010), é necessário considerar a interdependência campo-cidade, de maneira a não dicotomizar as duas realidades, para tanto os conceitos de prática social, trabalho e consciência de classe seriam essenciais nas investigações voltadas para a educação do campo.

11 Constata-se o crescente abandono da escola, sobretudo, quando os estudantes ingressam no ensino médio. De 3,3 milhões dos jovens ingressantes no ensino médio no ano de 2008, apenas 1,8 milhões concluíram esta modalidade no ano de 2010 (Anuário Brasileiro de Educação Básica, 2012). Os grupos etários majoritariamente atingidos são constituídos por adolescentes e jovens, além de maioria negra. Este quadro concentra-se entre alunos pobres, que sofrem mais, no contexto laboral, com as exigências de experiência anterior e maior qualificação não apenas técnica, mas básica (letramento e cálculo).

12 Vale dizer, que existe uma gama de estudos e pesquisas sobre as práticas educativas do campo que corroboram com esta perspectiva dialógica da educação inspirada em Paulo Freire ao enfatizarem "[...] a necessidade de uma metodologia de ensino baseada na valorização da cultura camponesa” (Souza, 2010).

\section{Referências}

ANUÁRIO Brasileiro da Educação Básica. 2012. Disponível em: <http://www.moderna.com.br/lumis/portal/file/fileDownload.jsp?fileId=8A8A8A83376FC2C901 3776334AAE47F0 >. Acesso em: 31 out. 2013.

ARENDT, Hannah. Entre o Passado e o Futuro. Tradução de Mauro W. Barbosa. 7. ed. São Paulo: Perspectiva, 2011.

BOURDIEU. Pierre. Meditações Pascalianas. Tradução de Sérgio Miceli. Rio de Janeiro: Bertrand Brasil, 2001.

CANCLINI, Nestor, Garcia. Consumidores e Cidadãos: conflitos multiculturais da globalização. Tradução: Maurício Santana. Rio de Janeiro: Editora UFRJ, 2010.

CARNEIRO, Maria José. Juventude Rural: projetos e valores. In: ABRAMO, Helena Wendel; BRANCO, Pedro Paulo Martoni (Org.). Retratos da Juventude Brasilei- 
Problematizando as Transições Juvenis na Saída do Ensino Médio

ra: análise de uma pesquisa social. São Paulo: Editora Fundação Perseu Abramo, 2005. P. 243-262.

DAYRELL, Juarez; CARRANO, Paulo. Juventude e Ensino Médio: quem é este aluno que chega à escola. In: DAYRELL, Juarez; CARRANO, Paulo; MAIA, Carla Linhares (Org.). Juventude e Ensino Médio: sujeitos e currículo em diálogo. Belo Horizonte: UFMG, 2014. P. 102-133. Disponível em: <http://educacaointegral. org.br/wp-content/uploads/2015/01/livro-completo_juventude-e-ensino-medio_2014.pdf>. Acesso em: 15 maio 2015.

DUBET, François. As Desigualdades Multiplicadas. Tradução de Sérgio Miola. Ijuí: Editora UNIJUI, 2003.

FORACCHI, Marialice M. A Juventude na Sociedade Moderna. São Paulo: Pioneira. Editora da Universidade de São Paulo, 1972.

GUERREIRO, Maria Dores da; ABRANTES, Pedro. Como Tornar-se Adulto: processos de transição na modernidade avançada. Revista Brasileira de Ciências Sociais, São Paulo, v. 20, n. 58, p. 157-175, jun. 2005. Disponível em: <http://www. scielo.br/pdf/rbcsoc/v20n58/25633.pdf>. Acesso em: 09 ago. 2013.

KRAWZCYK, Nora. Uma Roda de Conversa Sobre os Desafios do Ensino Médio. In: DAYRELL, Juarez; CARRANO, Paulo; MAIA, Carla Linhares (Org.). Juventude e Ensino Médio: sujeitos e currículo em diálogo. Belo Horizonte: UFMG, 2014. P. 7698. Disponível em: <http://educacaointegral.org.br/wp-content/uploads/2015/01/ livro-completo_juventude-e-ensino-medio.pdf>. Acesso em: 20 maio 2015.

MADEIRA, Felícia Reicher. Educação e Desigualdade no Tempo de Juventude. In: CAMARANO, Ana Amélia (Org.). Transição para a Vida Adulta ou Vida Adulta em Transição? Rio de Janeiro: IPEA, 2006. P. 139-169.

MANNHEIM, Karl. O Problema da Juventude na Sociedade Moderna. Tradução de Octavio Alves Velho. In: BRITTO, Sulamita de (Org.). Sociologia da Juventude, I: da Europa de Marx à América Latina de hoje. Rio de Janeiro: Zahar Editores, 1968. P. 69-94.

MARTUCCELLI, Danilo. Sociologies de la Modernité: l'itinéraire du XXe. Siécle. Paris: Gallimard, 2000.

MARTUCCELLI, Danilo. Cambio de Rumbo: La sociedad a escala delindividuo. 1. ed. Santiago de Chile: Lom Ediciones, 2007. Disponível em: <http://books.google. com.br/books?id=BqJXYWiNKQMC\&printsec=frontcover\#v=onepage \&q\&f=fal se>. Acesso em: 05 maio 2013.

MELUCCI, Alberto. Juventude, Tempo e Movimentos Sociais. Revista Brasileira de Educação, Rio de Janeiro, v. 5, p. 5-14, maio/ago. 1997. (Número especial Juventude e contemporaneidade).

MOLINA, Mônica. Entrevista com Especialista em Educação do Campo. Revista Nova Escola, São Paulo, n. 258, dez. 2012. Disponível em: <http://revistaescola. abril.com.br/politicas-publicas/entrevista-monica-molina-especialista-educacao-campo-732775.shtml>. Acesso em: 18 maio 2015.

PAIS, José Machado. Buscas de Si: expressividades e identidades juvenis. In: ALMEIDA, Maria Isabel Mendes de; EUGÊNIO, Fernanda (Org.). Culturas Jovens: novos mapas do afeto. Rio de Janeiro: Zahar, 2006. P. 7-21.

PAIS, José Machado. Jovens e Cidadania. Sociologia, Problemas e Práticas, Oeiras, n. 49, set. 2005. Disponível em: <http://www.scielo.gpeari.mctes.pt/scielo. php?script=sci_arttext\&pid=S0873-65292005000300004\&lng=pt\&nrm=iso $>$. Acesso em: 30 maio 2014.

132 Educação \& Realidade, Porto Alegre, v. 41, n. 1, p. 117-133, jan./mar. 2016. 
PAIS, José Machado. Culturas Juvenis. 2. ed. Lisboa: Imprensa Nacional-Casa da Moeda, 2003 (Temas Portugueses).

RIBEIRO, Eliane. Políticas públicas de Educação e Juventude: avanços, desafios e perspectivas. In: PAPA, Fernanda Carvalho de; FREITAS, Maria Virgínia (Org.). Juventude em Pauta: políticas públicas no Brasil. São Paulo: Petrópolis, 2011. P. 25-44.

SETTON, Maria da Graça Jacinto. A Particularidade do Processo de Socialização Contemporâneo. Tempo Social, São Paulo, v. 17, n. 2, p. 335-350, nov. 2005.

SETTON, Maria da Graça Jacinto. Experiências de Socialização e Disposições Híbridas de Habitus. In: DAYRELL, Juarez; NOGUEIRA, Maria Alice; RESENDE, José Manuel e VIERIRA, Maria Manuel (Org.). Família, Escola e Juventude: olhares cruzados Brasil-Portugal. Belo Horizonte: UFMG, 2012. P. 38-55.

SIMMEL, Georg. Questões Fundamentais da Sociologia: indivíduo e sociedade. Tradução de Pedro Caldas. Rio de Janeiro: Jorge Zahar Editor, 2006.

SOUZA, Maria Antônia. Educação e Movimentos Sociais do Campo: a produção do conhecimento no período de 1987 a 2007. Curitiba: Editora UFPR, 2010.

ZITTOUN, Tânia; VALSINER, Jaan; VEDELER, Damkert; SALGADO, Miguel M. Gonçalves; FERRING, Dieter. Human Development in the Life Course: melodies of living. Cambridge: Cambridge University Press, 2013.

ZITTOUN, Tânia; STANKOVIÇ, Biljana; BAUCA, Aleksandar. Uses of Symbolic Resources in Youth: moving from qualitative to quantitative approach. Psiholojiha, Beograd, v. 42, n. 4, p. 437-457, 2009.

ZIZEK, Slavoj. Problemas no Paraíso. Tradução: Nathalia Gonzaga. In: MARICATO, Ermínia et al. (Org.). Cidades Rebeldes: passe livre e as manifestações que tomaram as ruas do Brasil. 1. ed. São Paulo: Boitempo; Carta Maior, 2013. P. 101-108.

Denise Helena Pereira Laranjeira é professora da Universidade Estadual de Feira de Santana (UEFS). É doutora em Educação - Université de Sherbrooke - Québec (2005). Professora titular do Departamento de Educação da Universidade Estadual de Feira de Santana (UEFS); membro do Núcleo de Pesquisa Trajetórias, Culturas e Educação (TRACE-DEDU-UEFS)

E-mail: denise.laranjeira@gmail.com

Mirela Figueiredo Santos Iriart é doutora em Saúde Coletiva pela Universidade Federal da Bahia e Professora Titular do Departamento de Educação da Universidade Estadual de Feira de Santana (UEFS). Coordenadora do Núcleo de Pesquisa Trajetórias, Culturas e Educação (TRACE-DEDU-UEFS). Desenvolveu estágio pós-doutoral no Departamento de Psicologia na London School of Economic and Political Science.

E-mail: mifis36@gmail.com

Milena Santos Rodrigues é graduada em Pedagogia (2010), especialista em Desenho, com ênfase em Registro e Memória Visual (2012) e mestre em Educação pela Universidade Estadual de Feira de Santana. Professora da rede municipal de ensino em Bonfim de Feira.

E-mail: promirodrigues@gmail.com 